\title{
Polycarbonate microchannel network with carpet of Gold NanoWires as SERS-active device $\dagger$
}

\author{
Jean Gamby, ${ }^{* a}$ Aurore Rudolf, ${ }^{b}$ Mohamed Abid, ${ }^{c}$ Hubert H. Girault, ${ }^{d}$ Claude Deslouis ${ }^{a}$ and \\ Bernard Tribollet ${ }^{a}$
}

\author{
Received 21st November 2008, Accepted 20th February 2009 \\ First published as an Advance Article on the web 13th March 2009 \\ DOI: 10.1039/b820802f
}

A polycarbonate (PC) microchannel network supporting gold nanowires was developed to be a SERSactive microchip. Observations of large increases in a Raman cross-section, allowed us to collect vibrational signatures which are not easily detectable by Raman techniques due to the high fluorescence level of bare PC. Compared to other SERS experiments, this study relies on the use of dielectric polymer/metal surfaces which are well defined at microscale and nanoscale levels. This device seems a promising tool for sensing the adsorption of biomolecules.

In the last few years, polymer microchips have become highly desirable for on-site detection in areas such as life science, environment, food, and medicine. Until now, optical techniques were privileged due to their sensitivity and their non-destructive character. In this context, Surface-Enhanced Raman Scattering (SERS) is one of the most sensitive techniques for single molecule detection with regard to its molecular selectivity and specificity. ${ }^{1}$ With the same objective, Surface-Enhanced Hyper-Raman Scattering (SEHRS) was recently performed for applications of vibrational spectroscopy in biology. ${ }^{2}$ There is an abundant literature regarding SERS active substrates of silver or gold thin films (see for example ref. 3, 4). Among the various methods used for structuring surfaces, nanolithography ${ }^{5}$ and colloid adsorption $^{6-8}$ appear as the main two ones. Molecules adsorbed onto these nanostructured surfaces have shown an increase in enhancement factors of the order of $1 \times 10^{6}$ to $1 \times 10^{12}$ in terms of SERS efficiency. Following the latest published work on SERS nanoparticle tags, several groups have reached $1 \times 10^{15}$ in terms of efficiency using, as an example, a polymer encapsulation layer. ${ }^{9}$ In another field, metallization of polymer materials remains crucial in materials science engineering, especially for data storage of information. ${ }^{10}$ For example, an excimer laser in a photoablation procedure can be used to enhance adhesive properties of polymer-supported thin metallic films, ${ }^{11}$ and permits to obtain micrometre resolved cavities on thin metallic/ polymer films. Owing to the fact that recent breakthroughs ${ }^{6,12,13}$ were obtained in the synthesis and architecturing of

${ }^{a}$ Laboratoire Interfaces et Systèmes Electrochimiques, UPR 15 CNRS Casier 133, Université Pierre et Marie Curie, Paris 6, 4 place Jussieu, 75252 Paris Cedex 05, France. E-mail: jean.gamby@upmc.fr; Fax: +33 0144274074; Tel: +330144272125

${ }^{b}$ Institut de Physique de la Matière Condensée, IPMC-Station 3, Ecole Polytechnique Fédérale de Lausanne, CH-1015 Lausanne, Switzerland ${ }^{c}$ Angströmlaboratoriet, Universitet Uppsala, Lägerhyddsvägen 1, SE-751 21 Uppsala, Sweden

${ }^{d}$ Laboratoire d'Electrochimie Physique et Analytique, Ecole Polytechnique Fédérale de Lausanne, Faculté des Sciences de Base, Institut des Sciences et Ingénierie Chimiques, 1015 Lausanne, Suisse

$\dagger$ Electronic supplementary information (ESI) available: Materials and methods and Fig. S1. See DOI: 10.1039/b820802f nanomaterials, it would be interesting to integrate these materials into polymer microchannels.

A preliminary surface-enhanced Raman scattering investigation for a polymer microchip containing gold nanowires arrays is presented here. As illustrated in Fig. 1A, in order to integrate the nanowires into a microchannel, we synthesized gold nanowires using the electrocrystallization method into a track etched polycarbonate $(30 \mu \mathrm{m}$ thick) with an appropriate pore size and film thickness. Once this template filled, two layers of polyethyleneterephthalate ( $35 \mu \mathrm{m}$ thick) were thermally laminated on both sides of PC (see PET1 and PET2 in Fig. 1A). The PET/PC gold nanowire/PET system was exposed to an ArF excimer laser beam in order to create a deep cavity reaching the polycarbonate surface. The polycarbonate was partially removed for baring both ends of the vertical nanowires 3-D arrays by using $\mathrm{Ar}$ plasma etching. SEM-FEG micrographs showing the nanowires (NWs) network inside the microchannel are displayed in Fig. 1B. The average diameter of most NWs was estimated to be around $170 \mathrm{~nm}$ (Fig. 1C-D). At the end of plasma etching, the upper PC/ NWs/PET layer is covered to form a microchannel (Fig. 1A).

Upon recording the Raman spectrum of a $30 \mu \mathrm{m}$ thick bare PC sample, an unresolved fluorescence background was observed. Raman signals could no longer be discerned on top of the fluorescence background. However NWs doping PC microchannels can be used as substrates for SERS, where fluorescence is completely quenched, in agreement with the accepted model for the electromagnetic enhancement mechanism. ${ }^{14,15}$ To demonstrate resonant SERS, we exposed the microchannel PC/gold NWs to a buffer solution of perchloric acid $1 \times 10^{-3} \mathrm{M}$. The SERS spectra in Fig. 2A show clearly the $800-1600 \mathrm{~cm}^{-1}$ region of the Raman fingerprint of $\mathrm{PC}$ which is assigned to the $\mathrm{O}-\mathrm{C}-\mathrm{O}$ stretching and the aromatic ring breathing. As can be seen, five of the SERS bands show a significant intensity: the ring stretching at $1602 \mathrm{~cm}^{-1}$, the $\mathrm{O}-\mathrm{C}-\mathrm{O}$ stretching at $1230 \mathrm{~cm}^{-1}$, the in-plan $\mathrm{CH}$ wag at $1180 \mathrm{~cm}^{-1}$ and $1111 \mathrm{~cm}^{-1}$, and the $\mathrm{C}-\mathrm{CH}_{3}$ stretching at $888 \mathrm{~cm}^{-1} \cdot{ }^{14-16}$ Obtention of a SERS fingerprint of the polycarbonate molecules, which was not easily detectable by traditional Raman techniques, underlines that there exists substantial interaction between the deposited gold NWs and the polycarbonate matrix. In this case, one can assume that a resonant 

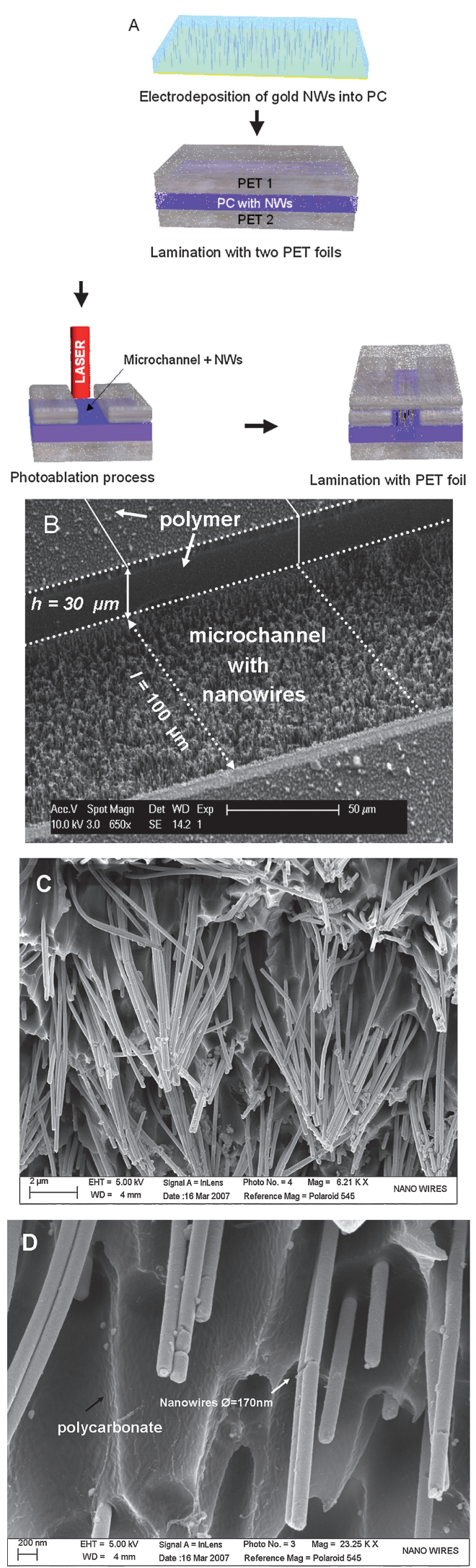

Fig. 1 (A) Schematic illustration for the fabrication of the microchannel network with embedded gold nanowires 3-D arrays. (B) SEM micrograph of microchannel containing metallic nanowires. (C, D) SEM-FEG at higher magnification after selective plasma etching of polycarbonate.
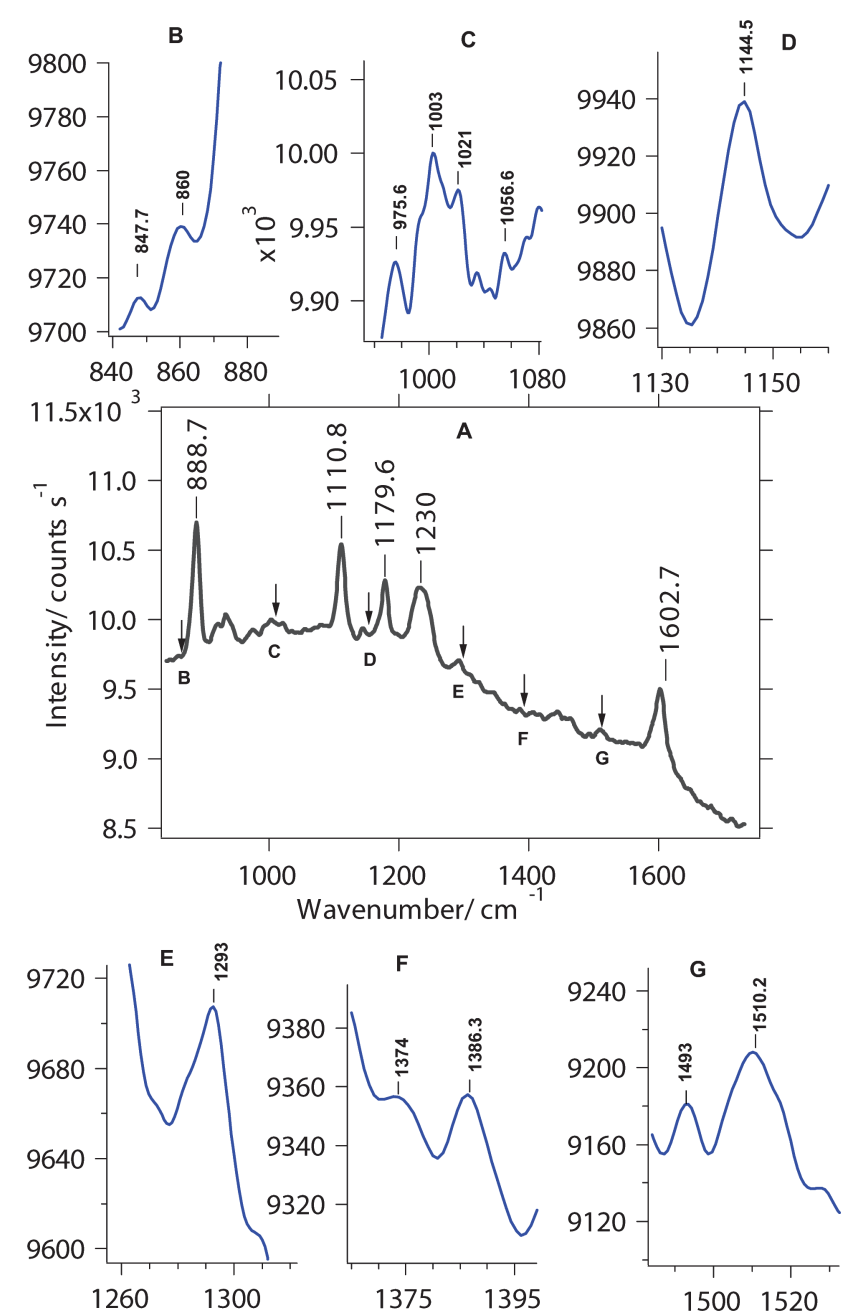

Fig. 2 (A) SERS spectra of a modified polycarbonate membrane by gold NWs insertion. (B), (C), (D), (E), (F) and (G) SERS spectra of isonicotinic acid $\left(1 \times 10^{-5} \mathrm{M}\right)$ in perchloric acid $\left(1 \times 10^{-3} \mathrm{M}\right)$ with graph $\mathrm{A}$ as signal background (see text).

SERS (SERRS) occurs with a contribution of the polymer's absorption which exists through the chromophoric units on the polycarbonate chain. Nevertheless, the SERS spectrum predominantly originates from the enhanced signals generated by the deposited gold NWs.

The first experiments displayed in Fig. 2 B-G, represent the result of adding $1 \times 10^{-5} \mathrm{M}$ of pyridine carboxylic acid (isonicotinic acid, INA) in $1 \times 10^{-3} \mathrm{M}$ perchloric acid aqueous solution. Experimental SERS spectra of isonicotinic acid adsorbed on gold nanowires are in good agreement with the literature. ${ }^{17-19}$ These bands located in the background level of SERS PC/gold NWs exhibit the following features: $847 \mathrm{~cm}^{-1}$ (out-of-plane ring vibration, (Fig. 2B); three bands around 1010 $\mathrm{cm}^{-1}$ (in-plane ring breathing mode, Fig. $2 \mathrm{C}$ ); $1056.6 \mathrm{~cm}^{-1}$ ( $\beta$ $(\mathrm{NH})$ mode, Fig. 2C); $1144.5 \mathrm{~cm}^{-1}$ (CH in-plane vibration mode, Fig. 2D); and $1386.3 \mathrm{~cm}^{-1}$ which is a combination effect of $v \mathrm{~s}(\mathrm{COO}), \beta(\mathrm{CH})$ and $\beta(\mathrm{NH})$ (Fig. $2 \mathrm{~F})$ ). It is interesting to note that the relative weak intensity of the band at $1386.3 \mathrm{~cm}^{-1}$ compared with bands at $1293 \mathrm{~cm}^{-1}$ and $1510 \mathrm{~cm}^{-1}$ show off an adsorption of the cationic form of INA (Fig. 2E and G)), 
indicating that adsorption occurs via donation of $\pi$-system electrons. ${ }^{17,18}$ This latter point is in agreement with our experimental acidic $\mathrm{pH}$ condition. To test the SERS performance of the NWs-doped polycarbonate microchannel, some organic compounds are in process as samples for SERS measurements.

To conclude, polycarbonate is a cheap raw material easy to process and well adapted for large scale production. These wellbalanced technologic and economic advantages of this kind of SERS-active in dielectric polymer/NWs made it a good candidate for microchip integration. A great advantage in the microdevice domain is that a large surface to volume ratio in the channel can dramatically increase the sensitivity. Therefore, the system can be employed for a "multi-use and multivariety" detection due to the fact that in a low concentration regime, the adsorption of biomolecules on modified gold nanomaterials or on polymer is reversible and depends on the surface charge of the microchannel surface. ${ }^{20}$ Since most of the biological molecules, such as proteins and DNA, are charged under physiological conditions, the device is appropriate to detect and study the adsorption of a variety of biomolecules onto the surface of the nanowires.

This material is based upon work supported by the European Science Foundation through action "COST D33". The authors thank Marie-Claude Bernard, Dr Suzanne Joiret for their guidance on Raman spectroscopy and Stephan Borensztajn for SEMFEG micrographs acquisition.

\section{References}

1 M. Fleischmann, P. J. Hendra and A. J. McQuillan, Chem. Phys. Lett., 1974, 26(2), 163-6.

2 J. Kneipp, H. Kneipp and K. Kneipp, Chem. Soc. Rev., 2008, 37, $1052-1060$

3 Y. C. Cao, R. Jin and C. A. Mirkin, Science, 2002, 297(5586), 15361540 .
4 J. P. Goudonnet, J. L. Bijeon, R. J. Warmack and T. L. Ferrell, Phys. Rev. B: Condens. Matter Mater. Phys., 1991, 43(6), 4605-12.

5 R. Alvarez-Puebla, B. Cui, J.-P Bravo-Vasquez, T. Veres and H. Fenniri, J. Phys. Chem. C., 2007, 111(18), 6720-6723.

6 A. Tao, F. Kim, C. Hess, J. Goldberger, R. He, Y. Sun, Y. Xia and P. Yang, Nano Lett., 2003, 3(9), 1229-1233.

7 J. T. Krug, II, G. D. Wang, S. R. Emory and S. Nie, J. Am. Chem. Soc., 1999, 121(39), 9208-3214.

8 S. Santesson, J. Johansson, L. S. Taylor, I. Levander, S. Fox, M. Sepaniak and S. Nilsson, Anal.Chem., 2003, 75(9), 2177-2180.

9 X.-M. Qian and S. M. Nie, Chem. Soc. Rev., 2008, 37, 912-920.

10 H. Horn, S. Beil, D. A. Wesner, R. Weichenhain and E. W. Kreutz, Nucl. Instrum. Methods Phys. Res., Sect. B., 1999, 151(1-4), 279284.

11 P. E. Dyer, R. J. Farley, R. Giedl and D. M. Karnakis, Appl. Surf. Sci., 1996, 96-98, 537-549.

12 (a) A. R. Tao and P. Yang, Journal of Physical Chemistry B., 2005, 109(33), 15687-15690; (b) D. J. Sirbuly, A. Tao, M. Law, R. Fan and P. Yang, Adv. Mater., 2007, 19(1), 61-66.

13 B. R. Flachsbart, K. Wong, J. M. Iannacone, E. N. Abante, R. L. Vlach, P. A. Rauchfuss, P. W. Bohn, J. V. Sweedler and M. A. Shannon, Lab Chip., 2006, 6(5), 667-674.

14 S. Keller and J. Heintzenberg, J. Aerosol Sci., 1997, 28(1), S609-S610.

15 K. Wang and Y.-S. Li, Vib. Spectrosc., 1997, 14(2), 183-188.

16 J. Dybal, P. Schmidt, J. Baldrian and J. Kratochvil, Macromolecules, 1998, 31(19), 6611-6619.

17 J. Barthelmes and W. Plieth, Electrochim. Acta., 1995, 40(15), 24872490.

18 P. Koczon, J. Cz. Dobrowolski, W. Lewandowski and A. P. Mazurek, J. Mol. Struct., 1998, 31(19), 6611-6619.

19 (a) R. Wen and Y. Fang, J. Colloid Interface Sci., 2005, 292, 469-475; (b) L.-R. Wang and Y. Fang, Chem. Phys., 2006, 323, 376-382.

20 (a) J. Gamby, J.-P. Abid and H. H. Girault, J. Am. Chem. Soc., 2005, 127, 13300-13304; (b) J. Gamby, J.-P. Abid, M. Abid, J-.P. Ansermet and H. H. Girault, Anal.Chem., 2006, 78(15), 5289-5295; (c) J. Gamby, M. lazerges, C. Pernelle, H. Perrot, H. H Girault and B. Tribollet, Lab Chip, 2007, 7(11), 1607-1609; (d) J. Gamby, J.-P. Abid, B. Tribollet and H. H. Girault, Small., 2008, 4(6), 802-809; (e) J. Gamby, M. Lazerges, H. H Girault, C. Deslouis, C. Gabrielli, H. Perrot and B. Tribollet, Anal.Chem., 2008, 80(23), 8900-8907. 